\title{
DESENVOLVIMENTO HUMANO E O "SER DOCENTE": CONCEPÇÕES A PARTIR DA EXPERIÊNCIA DE EDUCADOR COM UMA TURMA DE SEXTO ANO
}

\author{
Human Development and the "Being a Teacher": conceptions of an \\ educator's experience with a 6th grade class
}

\author{
Gustavo Pedroso de Moraes (gustavo.botanica@gmail.com) \\ Instituto Federal Farroupilha - Campus Panambi \\ Fabiana Lasta Beck Pires (fabiana.pires@iffarroupilha.edu.br) \\ Instituto Federal Farroupilha - Campus Panambi \\ Graciele Dotto Castro (graciele.castro@iffarroupilha.edu.br) \\ Instituto Federal Farroupilha - Campus São Vicente do Sul
}

\begin{abstract}
Resumo: Para o exercício da docência é necessário voltar-se às metodologias, ferramentas e avaliações de ensino, como também conhecer o aluno e entendê-lo como um sujeito biopsicossocial. Isso porque o desenvolvimento humano interfere diretamente no processo de aprendizagem dos discentes, uma vez que esses sofrem influências biológicas, psicológicas e sociais durante toda a sua formação. Este trabalho tem o objetivo de pensar o contexto escolar por meio de ferramentas teóricas da psicanálise e da educação sobre o desenvolvimento humano e o âmbito escolar. O trabalho trata-se de um Relato de Experiência com abordagem qualitativa, realizado em uma turma de 21 alunos de sexto ano do Ensino Fundamental durante o período de regência de estágio curricular supervisionado obrigatório. As observações realizadas foram registradas no Diário de Campo e interpretadas pelo método de Análise de Conteúdo. Os resultados observados apontam que as mudanças biológicas e psíquicas interferem no processo de aprendizagem, principalmente quando há grande variação de idade em uma turma. Para finalizar, no contexto apresentado, foram destacadas as estratégias utilizadas frente aos desafios que surgiram durante as aulas, situações que colocaram os alunos em posição de reconhecimento, possibilitaram autonomia e lugar ativo no processo de aprendizagem.
\end{abstract}

Palavras-chave: desenvolvimento humano; adolescência; docência; educação; aprendizagem.

Abstract: For efficient teaching, it is necessary to turn to teach methodologies, tools, and assessments, as well as to know the student and to understand him/her as a biopsychosocial subject. That's because, human development interferes directly in the learning process of the students since they undergo biological, psychological and social influences throughout their formation. This work aims to think about the school context through theoretical tools of psychoanalysis and education about human development and school scope. The work is a case experience report a qualitative approach, carried out in a class of 21 students from the sixth year of an elementary school during the period of 
compulsory internship. The observations were recorded in an ethnographic field diary that we called Diário de Campo and interpreted by the Content Analysis method. The observed results indicate that biological and psychic changes interfere in the learning process, especially when there is a great variation of age in a class. Finally, in the context presented, the strategies used in face of the challenges that emerged during the classes were highlighted, situations that placed the students in a position of recognition enabled autonomy and an active place in the learning process.

Keywords: human development; adolescence; teaching; education; learning.

\section{INTRODUÇÃO}

Preocupar-se com as metodologias, ferramentas e meios de ensino são alguns aspectos a serem pensados pelo docente ao exercer a sua função. Compreender o aluno e entender a heterogeneidade de cada turma também são de suma importância para o exercício da docência. $\mathrm{O}$ docente desempenha papel fundamental na formação humana do sujeito, uma vez que educamos para a vida ou mundo e não apenas para o mercado do trabalho. Dessa forma, é imprescindível levar em conta as vivências atuais (os diversos elementos que podem interferir no percurso da aprendizagem), a história e as condições socioeconômicas dos discentes, analisando como esses fatores podem vir a interferir no processo de ensino e aprendizagem do sujeito.

Para autores como Piaget (1970) e Wallon (1995) o ser humano pode ser definido - sem excluir fatores que cada teórico destacou em sua teoria - um ser biopsicossocial. Dessa forma, entende-se que somos influenciados por fatores biológicos, psicológicos e sociais ao longo da vida. Esses fatores do desenvolvimento integral do ser humano, muitas vezes, são passados despercebidos pelo docente, pois não há a compreensão do indivíduo como um sujeito completo. As teorias piagetianas destacam que o sujeito desempenha um papel ativo no seu próprio desenvolvimento e para melhor desenvolver as habilidades de aprendizagem é de extrema importância que o professor considere os processos do desenvolvimento humano, entendendo que os aspectos biológicos, cognitivos e socioemocionais interferem diretamente no desempenho escolar do aluno.

Corroborando esses aspectos, no contexto da psicanálise, Freud descreve as fases do desenvolvimento psicossexual (da evolução libidinal, para onde a energia do sujeito está voltada). Nessas fases do desenvolvimento o sujeito é afetado, principalmente, por 
alterações biológicas e influenciado pela sexualidade (libido sexual). Na interação das forças internas e externas há a constituição do sujeito (FREUD, 1996), ou seja, o corpo humano passa por diferentes alterações biológicas ao longo da vida, em especial na infância e na adolescência, períodos em que ocorre a maturação orgânica. A criança e o adolescente vivem desamparos em decorrência das mudanças sentidas como ataques originários do mundo interno (por exemplo, a fome que causa sensação de desprazer) e do mundo externo. Cada etapa de vida reedita o que foi desenvolvido no período anterior, isto é, na adolescência há a reelaboração de questões vividas na infância pois, como afirma Freud (2017), na vida psíquica o que se formou em dado momento não desaparece, o aparelho psíquico constrói estruturas em tempos diferentes (como se fosse em dimensões paralelas) sobre a mesma base. Isso porque, em cada etapa, nosso aparelho psíquico precisa elaborar as diferentes demandas que surgem interna e externamente. Portanto, cada uma das fases da vida e do desenvolvimento psicossexual desempenha importante papel no desenvolvimento da personalidade do sujeito (FREUD, 2004).

A partir de inquietações da prática docente, o presente trabalho objetiva pensar o contexto escolar observado por meio de ferramentas teóricas importantes, as quais abordam o desenvolvimento humano e os fatores que influenciam o processo de ensino e aprendizagem no âmbito escolar, por meio de um Relato de Experiência. Além disso, o artigo retratará algumas teorias do desenvolvimento humano, compreendida pelos autores como relevantes para a compreensão da temática e como elas podem vir a contribuir na percepção do aluno pelo olhar do professor. Salienta-se que é entendido que, epistemologicamente, alguns autores divergem em suas teorias, entretanto o trabalho objetiva apontar aquelas que auxiliaram na compreensão da prática. As observações para este estudo foram realizadas durante o período do estágio obrigatório ${ }^{1}$, em uma turma de sexto ano do Ensino Fundamental de uma escola pública situada no município de Panambi, Rio Grande do Sul.

\section{MATERIAIS E MÉTODOS}

${ }^{1}$ Estágio Curricular Supervisionado II, obrigatório, do Curso Superior de Licenciatura em Ciências Biológicas do Instituto Federal de Educação, Ciência e Tecnologia Farroupilha - campus Panambi. 
O presente trabalho trata-se de um Relato de Experiência (LÜDKE; ANDRÉ, 1986), que se embasa num modelo de investigação qualitativa, na qual o pesquisador busca uma compreensão do contexto no qual está inserido, de forma extensiva, com objetividade e validade conceitual. O estudo foi realizado durante o exercício de estágio em uma turma de sexto ano do Ensino Fundamental de uma escola pública situada no município de Panambi, Rio Grande do Sul, composta por 21 alunos, com idades entre 11 e 15 anos, no período de 09 de julho a 08 de outubro de 2018. As aulas foram ministradas sem a presença do professor supervisor da escola em sala de aula, em grande maioria, em dois períodos semanais, exceto duas, com quatro períodos, totalizando 36 horas aula (uma hora aula equivale a um período de 50 minutos), abordando o conteúdo de Botânica.

Durante as aulas foram realizadas observações de cada aluno, acompanhadas de registros mensais sobre o comportamento, a participação e aspectos relacionados ao desenvolvimento humano e a aprendizagem, com auxílio de Diário de Campo, relacionando as observações com a literatura específica acerca do assunto. Dos 21 alunos, definimos como amostra principal 12 estudantes. Os critérios utilizados para a escolha dos alunos foram o tipo de interação com o professor e os colegas, e o modo de participação nas aulas.

Como instrumento de coleta de dados foram utilizados registros em Diário de Campo. Este instrumento consiste em um diário de anotações, para o uso individual do investigador no seu dia a dia (FALKEMBACH, 1987). No diário são anotadas todas as observações, fatos concretos, fenômenos sociais, acontecimentos, relações verificadas, experiências pessoais do pesquisador, reflexões e comentários subjetivos (FALKEMBACH, 1987).

Para a análise dos dados utilizou-se o método de Análise de Conteúdo, uma técnica para ler e interpretar o conteúdo de documentos, que quando analisados adequadamente, nos abrem um leque de possibilidades de conhecimentos e fenômenos da vida social (OLABUENAGA; ISPIZÚA, 1989; LÜDKE; ANDRÉ, 1986, BARDIN, 2011). 


\section{O ALUNO COMO SUJEITO BIOPSICOSSOCIAL: BREVE REVISÃO TEÓRICA ${ }^{2}$}

Piaget (1970) afirma que o desenvolvimento do sujeito não se limita apenas ao processo biológico, mas relaciona-se às interações com o ambiente, ou seja, a construção de estruturas cognitivas é decorrente de interações do seu patrimônio genético (filo, onto e microgenético) com o ambiente. Para Freud, por sua vez, o desenvolvimento da personalidade está relacionado ao desenvolvimento da sexualidade (FREUD, 1996). Freud (1996) identificou cinco fases psicossexuais do desenvolvimento humano, quais sejam: Fase oral, Fase Anal, Fase Fálica, Período de Latência e o Estágio Genital. Neste trabalho serão abordadas as duas últimas fases, pois correspondem ao período de desenvolvimento dos alunos observados.

O Período de Latência é descrito como o momento de desenvolvimento transitório entre a Fase Fálica e o Estágio Genital. Caracteriza-se pela presença da energia sexual, a qual é direcionada para exercícios intelectuais e interações sociais em que o sujeito aprende a se relacionar socialmente e, também, a ter autoconfiança (FREUD, 1996). Na etapa de desenvolvimento seguinte, o Estágio Genital, que começa com a chegada da puberdade, o indivíduo volta a libido sexual para um objeto externo e amplia o reconhecimento das necessidades dos outros sujeitos, cedendo às demandas do outro para ser aceito por um par afetivo e no pertencimento ao grupo (FREUD, 1996).

Wallon (1995) e Piaget (1970), cada qual a seu turno, entendem o sujeito como um indivíduo completo, considerando de forma igualitária as esferas afetivas, cognitivas e motoras e a sua relação com o meio. De acordo com Wallon (1995):

\footnotetext{
é contra a natureza tratar a criança fragmentariamente. Em cada idade, ela constitui um conjunto indissociável e original. Na sucessão de suas idades, ela é um único e mesmo ser em curso de metamorfoses. Feita de contrastes e de conflitos, a sua unidade será por isso ainda mais suscetível de desenvolvimento e de novidade (WALLON, 1995, p.135).
}

\footnotetext{
${ }^{2}$ Novamente salienta-se que o estudo não se trata de interface teórica, uma vez que o objetivo não é comparar teorias, mas sim apresentar as que contribuíram para a compreensão do sujeito nesse estudo de caso.
} 
Portanto, ressalta-se a importância do compreender o aluno como um sujeito integral, ou seja, um indivíduo biopsicossocial, uma vez que o processo de aprendizagem do aluno será influenciado diretamente pelos diversos fatores que o cercam.

\section{DA POSTURA DE ENFRENTAMENTO À DEPENDÊNCIA: APRESENTANDO A TURMA}

A turma observada apresentava comportamento de constante interação extra conteúdos de aula, situação que dificultava o trabalho docente e o desenvolvimento acadêmico dos discentes no momento inicial do período de aula. Outro fator que influenciou o desenvolvimento das atividades curriculares, foi o horário e o dia da disciplina, a qual ocorria nos primeiros dois períodos das manhãs de segunda-feira, momento de reencontro dos estudantes, no qual se manifestava o desejo de interação com entre os discentes, em especial, para fazer relatos sobre as experiências vivenciadas no final de semana. A turma, salvo quando eram solicitados a sentar em grupos, era organizada em filas. Mesmo com essa disposição e distância entre as carteiras, as conversas paralelas ocorriam com os colegas próximos e com os mais distantes fisicamente.

Segundo relato dos demais professores, quando a maioria da turma estava no quinto ano, nesta escola ocorrendo no turno da tarde, os alunos eram mais dedicados e participavam da aula ativamente, situação que mudou quando foram para o sexto ano, no turno da manhã. $O$ fator preponderante que parece influenciar nessa alteração de comportamento é o fato de que o sexto ano é um período de transição quando, além das transformações biológicas e hormonais, há a transição do currículo escolar, sendo que até o $5^{\circ}$ ano um docente da Pedagogia ministrava a disciplina de Ensino Globalizado, e quando entram no $6^{\circ}$ ano conhecem uma nova estrutura que consiste na distribuição por áreas do conhecimento, com vários docentes que trabalham, cada qual, sua área formativa. Além disso, segundo a Teoria da Aprendizagem Social, proposta por Albert Bandura (BANDURA, 2001), fala que experiências diretas e experiências vicariantes ${ }^{3}$

\footnotetext{
${ }^{3}$ Experiências diretas são tidas como a fonte principal de influência da autoeficácia, constituindo-se pela interpretação dos resultados de uma performance realizada. Experiências Vicariantes: as pessoas são
} 
determinam a gama de comportamentos disponíveis pelo ser humano. Dessa forma, entende-se que os alunos, de maneira geral, ao trocarem de turno e conviverem com colegas mais velhos (tanto os alunos repetentes, quanto os de outras turmas), passaram a ter comportamentos diferentes dos que tinham quando estudavam à tarde, com colegas mais novos.

A partir dos Diários de Campo, com as anotações feitas com base na observação de cada aluno, foram escolhidos 12 sujeitos. A seguir será apresentada uma breve descrição dos alunos escolhidos como amostra:

- Aluno 1 (12 anos): aluno repetente. No começo tinha muita dificuldade de ficar em silêncio, não respeitando o professor e colegas. Apresenta histórico de problemas com outros professores. Durante o estágio mudou o comportamento, porém realizava as atividades rapidamente para poder conversar, o que causava dispersão da aula.

- Aluna 2 (13 anos): aluna repetente. Conversava muito, atrapalhando o andamento da aula e, no decorrer do estágio, foi ficando cada vez mais rebelde, utilizando palavras de baixo calão e com teor sexual.

- Aluno 3 (15 anos): aluno repetente, com histórico de problemas com professores e colegas, como desobediência, atitudes agressivas e direcionamento de palavras de baixo calão, porém, durante o estágio permanecia em silêncio, participando apenas quando solicitado. Em um certo período começou a recorrer sem necessidades ao auxílio de outro colega para realizar suas atividades, aproveitando-se, muitas vezes, de sua boa vontade, porém com o tempo foi notável seu esforço na disciplina.

- Aluna 4 (12 anos): a aluna não demonstrava interesse em realizar as atividades durante a aula. Utilizava o espaço escolar da sala para conversar com os colegas sobre temas extraclasse e, na maior parte do tempo em que conversava era por meio de gritos com a pessoa a quem se dirigia, situação que interferia na concentração dos colegas e no andamento da aula pelo professor.

influenciadas por seus pares, ou seja, a pessoa realiza uma tarefa, por exemplo, a partir de um modelo. Não se trata de uma imitação, mas sim de uma atitude semelhante à de alguém que o sujeito admira (RAPPAPORT; FIORI; DAVIS, 2014). 
- Aluna 5 (12 anos): aluna com bastante dependência do professor para a realização das atividades e avaliações. Seu excesso de conversa agitava bastante a turma, muitas vezes gritava com os colegas.

-Aluna 6 (13 anos): aluna com facilidade de aprendizagem, porém sua conversa e gritos com os colegas nas primeiras aulas acabavam atrapalhando. No decorrer do estágio demonstrou ser dedicada e com o bom uso de raciocínio lógico.

- Aluna 7 (11 anos): aluna dedicada e com facilidade de aprendizagem. Sua conversa e gritos atrapalhavam nas primeiras aulas, porém ao final do primeiro mês mudou o comportamento.

- Aluna 8 (15 anos): aluna repetente, com histórico de problemas familiares e carência socioeconômica. Não participava das aulas, sempre quieta. Seu rendimento escolar era muito prejudicado, pois não ia bem nas avaliações ou nas atividades de aula.

-Aluno 9 (14 anos): aluno repetente, com histórico de problemas escolares, familiares e socioeconômicos. Mostrava-se "nervoso", gritando com os demais colegas e professores. Não se interessa por todos os assuntos trabalhados em aula.

- Aluna 10 (12 anos): aluna dependente do professor, não costumava socializar com os demais colegas. Começou o estágio demonstrando potencial no processo de aprendizagem, porém com o tempo não conseguiu resolver as atividades propostas sem a ajuda do professor.

- Aluno 11 (11 anos): aluno dedicado, realizava todas as atividades com maestria, demonstrando domínio do conteúdo nas contribuições para a aula. Não apresentou dificuldades de aprendizagem

- Aluno 12 (12 anos): aluno dedicado. Apesar da conversa, realizava todas as atividades e contribuiu ativamente na aula, não apresentando dificuldades de aprendizagem.

\section{O ALUNO COMO SUJEITO INTEGRAL: O INDIVÍDUO COMO SER BIOPSICOSSOCIAL}


$\mathrm{Na}$ pré-adolescência e adolescência diversas variáveis interferem no desenvolvimento integral do aluno. As transformações biológicas e sociais, por exemplo, interferem diretamente no comportamento do sujeito, bem como no seu processo de aprendizagem, uma vez que a maioria dos alunos (no contexto desta turma) está entrando na etapa da puberdade e relacionando-se com indivíduos que também estão nesse período, estabelecendo-se em pequenos grupos sociais, buscando a aceitação do outro. Segundo Levisky (1998), a adolescência é identificada por uma revolução biopsicossocial, uma vez que o sujeito está transitando para a fase adulta. Esse período é marcado por desequilíbrios e instabilidades extremas (KNOBEL, 1981), sendo que todos os processos são fundamentais para o desenvolvimento humano, pois a partir deles será estabelecida a identidade de cada sujeito.

A partir da experiência docente, foi possível observar que os alunos mais novos tentam se aproximar dos mais velhos como se tivessem uma profunda admiração por estes. E, a partir disso, na turma, alguns alunos que antes - segundo relatos dos professores do ano anterior ${ }^{4}$ - eram mais dedicados aos estudos e participavam das aulas, passam a apresentar comportamentos totalmente diferentes dos observados no ano anterior, como a rebeldia. Alguns alunos eram mais rebeldes que outros, pois desobedeciam às normas escolares e faltavam com respeito em relação aos professores e colegas. Os adolescentes tendem a contrariar ordens e regras, em busca de demonstração de autonomia (a qual, muitas vezes, não é reconhecida pelos adultos); porém, por outro lado, por estarem em um período de transição para a vida adulta (fase em que os adultos ora os tratam como crianças e ora os cobram como adultos), tendem a oscilar esse comportamento de autonomia com comportamentos voltados à fase de vida anterior (CALLIGARIS, 2014), como nos momentos em que demandam cuidados e confirmações do outro, indicando dependência do adulto (pais, responsáveis e professores).

Segundo Erikson (1972), conflitos como esses fortalecem a identidade no processo de construção. Sendo assim, existe uma busca constante pela identidade, na qual o adolescente procura participar de grupos cujas maneiras de pensar e agir são parecidas

\footnotetext{
${ }^{4}$ Como os alunos não foram acompanhados nos anos anteriores, fez-se necessária conversa sobre as posturas dos alunos, como forma de análise. Saliento que o período de estágio (observação e regência) não ofereceria subsídios para analisar os aspectos abordados no texto.
} 
com a sua [na maioria dos casos]. Esse processo foi chamado por Maurício Knobel de Tendência Grupal (KNOBEL, 1981). Corroborando tal interpretação, à luz da Psicanálise, o Período de Latência é identificado pela necessidade do sujeito de constituir relações sociais, ou seja, é necessário estabelecer-se em grupos, buscando assim a aceitação do outro (FREUD, 1996). Dessa forma, mesmo que os comportamentos dos alunos mais velhos não fossem os mesmos ao de alguns dos alunos da turma, estes sentiam a necessidade de se agrupar, de modo a sentir-se parte de algo, ou seja, um grupo social.

O Aluno 1, por exemplo, costumava dispersar bastante nas primeiras aulas observadas, fazendo brincadeiras desnecessárias, não aceitando pedidos de silêncio, o que pode ser observado como forma de chamar a atenção para si. Um dos possíveis fatores a influenciar nesse caso poderia ser identificado como o contexto familiar, embora saibamos que todos os fatores envolvidos, sobretudo os que controlam o comportamento imediato (ações dos professores e ambiente escolar) influenciam esse aspecto.

Segundo Drummond e Drummond Filho (1998), o grupo familiar exerce grande influência na constituição do sujeito, ajudando na formação e organização da personalidade. $\mathrm{O}$ autor também contribui afirmando que é nesse contexto que o indivíduo é influenciado significativamente no comportamento individual por meio das ações e medidas educativas tomadas no âmbito familiar.

Comportamento similar foi observado na Aluna 2. Suas atitudes geravam tensões e discussões entre os colegas de classe. Na maior parte das interações com o professor, sua postura era de enfrentamento. Ela manifestava interação com discurso provocativo em relação ao Aluno 3, que era o mais velho da turma, com histórico de reprovação. A Aluna 2 , também, não havia avançado de ano em outra escola. Relatos da equipe pedagógica ${ }^{5}$ escolar indicavam que a aluna passava por dificuldades familiares, referente aos aspectos socioeconômicos e no âmbito das relações interpessoais, situação que apontava influenciar diretamente no seu processo de aprendizagem. Em resposta ao discurso da Aluna 2, o Aluno 3 reagia com uso de palavras e expressões inapropriadas ao ambiente

\footnotetext{
${ }^{5}$ Novamente houve a necessidade de um diálogo coletivo no contexto escolar, pois por meio dessas conversas que foi possível conhecer mais sobre os alunos.
} 
escolar e, muitas vezes, com teor sexual. Além disso, ele não costumava sentar com outros colegas ou socializar durante as aulas, participando apenas quando era solicitado.

De Paula (2009) afirma que o contexto familiar (fatores extraescolares: podem ser relacionados a má qualidade de vida), bem como o escolar (fatores intra-escolares: relacionados aos programas, trabalhos e relações desenvolvidas na escola), contribui para o processo de aprendizagem do aluno, ou seja, se não for um contexto saudável pode contribuir para o fracasso escolar, sendo assim, estimulando a evasão e repetência do aluno. Além disso, segundo Gualtieri e Lugli (2012), o preconceito dos colegas e professores pode influenciar os alunos repetentes, ou com problemáticas sociais, favorecendo nestes o surgimento de pensamentos de incompetência por parte do aluno. Ao encontro disso, não somente como causa da repetência, esses fatores podem também influenciar o comportamento inoportuno em sala de aula.

Em conversa informal com o Aluno 3, este verbalizou que não se sentia bem em relação aos outros alunos da turma, pois seus colegas apresentavam atitudes infantis. Para este aluno, era notável como a falta de pessoas que pensassem como ele (grupo de identificação), acabava prejudicando seu processo de aprendizagem, pois este não conseguia se "encaixar" no contexto coletivo. Wallon (1986) explica que o desenvolvimento humano acontece a partir do coletivo, pois somos geneticamente sociáveis, ou seja, o Eu depende do Outro ${ }^{6}$. Destarte, não observamos comportamento de busca ou interação com pares, o que tornava o seu processo de aprendizagem menos prazeroso.

As alunas 4, 5, 6 e 7 formavam um grupo dentro da turma, apresentando comportamento similar entre si, com conversa frequente, sendo comum gritar e atrapalhar a aula. Essa interação grupal é importante, pois, como aponta Calligaris (2014), com os pares do grupo, os adolescentes se reconhecem mutuamente (reconhecimento que não recebem dos adultos). Nesse grupo, a Aluna 8 exerceu grande influência sobre as demais

\footnotetext{
${ }^{6} \mathrm{O} \mathrm{Eu}$ se constitui a partir do Outro primordial, que na infância remonta os pais ou cuidadores. Na adolescência as encarnações do Outro primordial entram em crise, situação denominada por Rassial (1995) de operação adolescente. Nessa operação o adolescente reorganiza e realoca as encarnações do Outro primordial, de forma a criar uma nova consistência de ordem imaginária, do Outro como a sociedade e a natureza.
} 
colegas. Ela retornou às aulas após um período de ausência por motivo de ordem pessoal na metade do estágio e, após esse período, as discentes que formavam o supracitado grupo se aproximaram dela. As interações entre essas meninas eram caracterizadas por conversas paralelas ao conteúdo da disciplina e de risos, o que demonstrava demarcar o espaço de reconhecimento de grupo, excluindo os demais presentes na sala. No último mês, essas alunas começaram a realizar perguntas sobre sexualidade logo após as conversas com a Aluna 8. Essas perguntas eram realizadas usando, muitas vezes, do recurso da ironia, pois vinham acompanhadas de risos e, em certos casos, observou-se que elas já sabiam a resposta, parecendo ter como objetivo constranger a figura do professor. Somando-se a isso, a Aluna 4 não prestava atenção na aula, demonstrando pouco interesse pela disciplina e na realização das atividades propostas. Na maioria das situações em que foi chamada a atenção da aluna, foi porque estava com o espelho, ou até mesmo retocando a maquiagem.

Levando em conta a influência da Aluna 8 sobre o Aluno 9 (que já apresentava comportamentos que dificultavam a convivência em aula, como atos de desrespeito com os colegas e professor) este passou a influenciar ainda mais de forma negativa as aulas. Pôde ser observada alteração de comportamento por parte do aluno, quando ele passou a fazer brincadeiras com teor sexual com o Aluno 2, o qual parecia perturbar-se com tais brincadeiras. Com isso, este, que antes tinha atitudes que agitavam a aula, acabava atrapalhando ainda mais o andamento da disciplina. Quando o Aluno 2 resolvia participar das brincadeiras direcionadas pelo Aluno 9, entrava no mesmo padrão de comportamento, e utilizava palavras de baixo calão.

A partir dessa sequência de relatos em sala de aula, podemos observar que os alunos 2, 4, 5, 6 e 7, à luz de alguns elementos da teoria freudiana, estavam em transição entre o Período de Latência e a Fase Genital (uma vez que características de ambos estavam visíveis, mostrando interferência uma na outra), pois apresentavam comportamentos similares aos dois. Os alunos 3, 8 e 9, por seu turno, nitidamente estavam apenas na Fase Genital, sendo que principalmente os Alunos 8 e 9 exerciam influência sobre os demais, vistos por estes como exemplos para serem seguidos, devido a sua "maturidade sexual" ao tratar desses assuntos. 
Por outro lado, alguns alunos eram totalmente dependentes do professor para a realização das atividades, demonstrando insegurança quanto à resolução das problemáticas trabalhadas em aula. Novamente essa dependência pode ser explicada a partir de teorias Piagetianas (RAPPAPORT; FIORI; DAVIS, 2014) sobre a adaptação da criança. Segundo elas, quando os alunos não são instigados pelo assunto da aula, ou até mesmo quando o conteúdo trata de uma temática nova, na qual ele não consegue resolver a partir de problemas já executados anteriormente, o estudante passa a ver o professor como ferramenta, pois supostamente é o método mais fácil para atingir o resultado final. Esse comportamento pode ser observado nas Alunas 5 e 10. Entretanto, a Aluna 5 precisava apenas da confirmação do professor, se estava certo ou errado o exercício realizado e se poderia prosseguir. Já a Aluna 10 necessitava da ajuda do professor para a realização de todas as atividades, demonstrando insegurança nas ações e um tempo demasiado maior para a realização das atividades.

Apesar de dependente para a realização de todas as atividades, nas primeiras aulas, a Aluna 10 contribuiu com afirmações pertinentes e coerentes à aula, porém com o decorrer do estágio começou a falar sobre assuntos que não apresentavam ligação com o conteúdo e, muitas vezes, sem nexo. Durante as avaliações, ficava emotiva e não conseguia interpretar as questões. As possíveis explicações/hipóteses que influenciavam no desenvolvimento e no rendimento escolar são que: 1 - Ela poderia estar passando por problemas no âmbito pessoal, familiar e social; 2 - dificuldade de entrosamento com os demais colegas, uma vez que ela não conseguia se encaixar em nenhum grupo; e 3 - Ela realizava essas afirmações para fugir do conteúdo, pois não sabia responder quando questionada, assumindo assim um comportamento de fuga diante das atividades que não conseguia realizar.

Por último, os Alunos 11 e 12 formavam o grupo dos alunos dedicados, que realizavam todas as atividades propostas e era nítida a vontade de impressionar o professor com as suas contribuições para a aula. Entretanto, o Aluno 12, em certos momentos, realizava brincadeiras com teor sexual dirigido para as meninas e também conversava durante as aulas. É importante ressaltar que esses alunos não deixavam o seu processo de aprendizagem ser influenciado por brincadeiras paralelas dirigidas a eles, 
aproveitando o tempo em aula para estudar, uma vez que formavam um grupo fechado para os demais.

\section{A Heterogeneidade dA TURMA: O QUE A PRÁtica NOS ENSINA?}

A turma observada era constituída por alunos de diversas idades, entendidos como sujeitos Biopsicossociais. Como resultado dessa constituição heterogênea, vários desafios para o processo de ensino e aprendizagem surgiram, como a postura de enfrentamento, a conversa exagerada, a falta de interesse e a dependência excessiva para realização das atividades escolares. Mas como superar esses obstáculos? Durante o exercício da docência no estágio as soluções mais viáveis, foram atividades variadas levando em conta a heterogeneidade e particularidade da turma: os próprios grupos sociais préestabelecidos na sala. Para superar esses desafios, as seguintes metodologias foram utilizadas:

Saídas de Campo e Atividades Práticas: essas atividades não excluíram ou isolaram os grupos formados na sala, uma vez que a socialização do que estava sendo observado naquele momento permitia o compartilhamento em grupo e compreensão de forma coletiva. Além disso, designar líderes (alunos mais velhos, por exemplo) para a fiscalização do trabalho, pois estes poderiam ver a repetência de ano como uma forma de poder ajudar os colegas. Corroborando a isso podemos citar trabalhos como de Coutinho e Miranda (2019), que ressaltam a importância de atividades práticas nas aulas de Ciências da Natureza.

Estudos de Problemática em Grupo: com questões abordando problemáticas referentes ao conteúdo estudado e buscando utilizar as relações afetivas da turma, o estudo de problemas proporcionou momentos nos quais os alunos discutiram e entraram em um consenso sobre a temática. Outro aspecto importante é que o professor pode atuar com postura que instigue os educandos ao desejo de conhecer, ao questionar e ir em busca de respostas, sem que façam uso direto do professor como único fornecedor de resposta para as questões e dúvidas que surgem na disciplina. $\mathrm{O}$ intuito aqui seria de incentivar o aluno a buscar recursos próprios e/ou externos (como no material didático, o diálogo com 
colegas ou em pesquisas) para criar um percurso de pensamento na construção de respostas às atividades de sala de aula ou para suas curiosidades acadêmicas. Para estimular o raciocínio e a construção de conhecimento dos alunos, pode-se utilizar os estudos de problemáticas em grupo.

Monitores da aula: para os alunos que conversavam bastante ou dispersavam a aula, designar tarefas para auxiliar no andamento das atividades propostas foi uma maneira de focar a energia em algo produtivo para o próprio aluno e para a turma, uma vez que este pode desempenhar um papel importante na aula e ativo em sua aprendizagem.

Além disso, essas metodologias exigiram mais da parte do aluno, instigando-os a buscarem de forma mais independente as respostas para a resolução das atividades ou concepções a partir das suas próprias observações. Essas propostas colocaram o aluno em um lugar de reconhecimento como sujeitos habilitados e em condições de serem ativos na sua aprendizagem, contribuindo assim para o desenvolvimento de sua autonomia e segurança. Como consequência, dois dos três alunos com comportamento transgressor mudaram suas atitudes positivamente, o que ocorreu somente depois de desempenharem papéis de monitores da aula, auxiliando a figura do professor. O outro aluno comparecia pouco às aulas, o que dificultou a relação professor-aluno e com a turma.

\section{CONSIDERAÇÕES FINAIS}

Como visto acima, a turma em questão variava em idade e em comportamentos. É essencial para o exercício da docência entender que cada um desses processos de formação (biológico, psicológico e social) é necessário para o desenvolvimento humano, pois principalmente na pré-adolescência e adolescência a identidade do sujeito está sendo construída. As relações interpessoais, fundamentais no desenvolvimento humano, bem como as alterações biológicas e psicológicas são necessárias na formação da personalidade e da identidade humana. Como os docentes fazem parte das relações interpessoais dos educandos, sendo um grande "Outro" do âmbito social, cabe ao profissional da educação buscar meios de contribuir na formação intelectual do aluno e no seu desenvolvimento como sujeito biopsicossocial. 
Para driblar os obstáculos, principalmente do Período da Adolescência, o professor pode instigar o aluno a focar sua energia dentro da sala de aula na formação intelectual, nesse caso, buscando conciliar de forma criativa os conteúdos, a fim de atrair a atenção e envolvimento da turma. Utilizar-se dos grupos sociais dentro do espaço escolar é uma forma para estimular o desenvolvimento intelectual do discente, uma vez que, possivelmente trabalhando com colegas próximos, o aluno terá um melhor processo de aprendizagem.

Com base no exercício do estágio de docência observou-se que trazer atividades práticas de laboratório e de campo chamava a atenção e conseguia manter os alunos focados, na maioria dos casos, porém as atividades não poderiam ser monótonas. Além disso, para os alunos mais velhos, proporcionar momentos em que pudessem ser líderes instigava-os a interagir de forma mais ativa na sala de aula.

Outro aspecto importante é que o professor pode atuar com postura que instigue os educandos ao desejo de conhecer, ao questionar e ir em busca de respostas, sem que façam uso direto do professor como único fornecedor de resposta para as questões e dúvidas que surgem na disciplina. O intuito aqui seria de incentivar o aluno a buscar recursos próprios e/ou externos (como no material didático, o diálogo com colegas ou em pesquisas) para criar um percurso de pensamento na construção de respostas às atividades de sala de aula ou para suas curiosidades acadêmicas. Para estimular o raciocínio e a construção de conhecimento dos alunos, pode-se utilizar os estudos de problemáticas em grupo.

O presente trabalho auxiliou na formação inicial do docente, uma vez que possibilitou pensar no exercício da docência para a formação de sujeitos biopsicossociais, ou seja, para além de uma educação apenas de cunho conteudista. Com isso, cria-se um espaço e margem para discussões transversais, que perpassam a área da educação, as quais contribuem para a constituição do sujeito em suas diversas esferas de vida. Um desses temas transversais que surgiu como demanda, após questões realizadas por alunos em sala de aula, foi em relação à sexualidade. Para articular a condução da resolução dessa demanda, a escola, juntamente com o estagiário, precisou buscar estratégias e conhecimento. O caminho encontrado foi o convite de professores especialistas da área de educação, gênero e sexualidade para debater com os alunos as perguntas propostas. Os 
sujeitos, nesse ambiente escolar em formação biopsicossocial, no ato de interação em sala de aula, foram o docente e os discentes.

\section{REFERÊNCIAS}

BANDURA, A. Social cognitive theory: an agentic perspective. Annual Review of Psychology, vol.52, n.1, p.1-26, 2001.

BARDIN, L. Análise de conteúdo. São Paulo: Edições 70. 2011.

CALLIGARIS, C. A adolescência (Coleção Folha Explica). $7^{\mathrm{a}}$ reimpressão. $2^{\mathrm{a}}$ ed. São Paulo: Publifolha, 2014, p.81.

COUTINHO, C.; MIRANDA, A.C.G. Formação inicial de professores de Ciências da Natureza: relatos de uma prática docente diferenciada. Revista Insignare Scientia-RIS, v. 2, n. 2, p. 221-231, 2019.

DE PAULA, V. M. S. R. Fracasso escolar: quem são os culpados? Paranaíba, 2009. Disponível em: <http://periodicos.uems.br/novo/index.php/anaispba/article/view File/150/85>. Acessado em: 02 nov. 2018.

DRUMMOND, M.; DRUMMOND FILHO, H. Drogas: a busca de respostas. São Paulo: Loyola, 1998.

ERIKSON, E. H. Identidade, juventude e crise. Rio de Janeiro: Zahar. 1972.

FALKEMBACH, E.M.F. Diário de campo: um instrumento de reflexão. Contexto e educação. Ijuí, RS Vol. 2, n. 7, p. 19-24. jul./set. 1987.

FREUD, S. Três ensaios sobre a teoria da sexualidade. In J. Strachey (Ed. E Trad.). Edição Standard Brasileira das Obras Psicológicas Completas de Sigmund Freud. Rio de Janeiro: Imago. Vol. 7, p 117-231. 1996.

FREUD, S. Formulações sobre os dois princípios do acontecer psíquico. In: Escritos sobre a psicologia do inconsciente. Coordenação geral de Luiz alberto Hanns. Rio de Janeiro: Imago Ed. 2004. p. 63-78, 
FREUD, S. O mal-estar na cultura. Tradução de Renato Zwick; revisão técnica e prefácio de Márcio Seligmann-Silva; ensaio bibliográfico de Paulo Endo e Edson Sousa. 2 ed. Porto Alegre, RS: L\&PM, 2017. 192p. - (Coleção L\&PM POCKET; v 850). GUALTIERI, R; LUGLI, R. A escola e o fracasso escolar. São Paulo: Cortez, 2012. KNOBEL, M. A síndrome da adolescência normal. In: Adolescência normal: Um enfoque psicanalítico, p. 24-62, 1981.

LEVISKY, D.L. Adolescência: reflexões psicanalíticas. 2. ed. São Paulo: Casa do Psicólogo, 1998. p. 69-83.

LÜDKE, M., ANDRÉ, M. E. D. A. Pesquisa em educação: abordagens qualitativas. São Paulo: EPU, 1986.

OLABUENAGA, J.I. R.; ISPIZUA, M.A. La descodificacion de la vida cotidiana: metodos de investigacion cualitativa. Bilbao, Universidad de deusto, 1989.

PIAGET, J. Epistemologia Genética. Tradução de Os Pensadores. Abril Cultural, 1970. RAPPAPORT, C.R.; FIORI, W.R.; DAVIS, C. Teoria do desenvolvimento. A idade escolar e a adolescência. Vol. 4. São Paulo, EPU, 2014.

RASSIAL, J-J. Entrevista com Jean-Jaques Rassial. Revista da Associação Psicanalítica de Porto Alegre, (11), p. 86-100. 1995.

WALLON, H; DE SOUSA, M.F. As origens do carácter da criança: os prelúdios do sentimento da personalidade. 1995. 